\title{
KEWAJIBAN PEMBERIAN BANTUAN HUKUM OLEH ADVOKAT DALAM KEDUDUKANNYA SEBAGAI OFFICIUM NOBILE
}

\author{
Urip Putranto \\ STIH dan HAM Parigi Sulteng
}

\begin{abstract}
Provision of legal aid is an obligation attached by law to any advocate in his capacity as a noble profession (officium nobile). This study aimed to understand (1) the implementation of the legal aid advocates to people seeking justice, (2) the supervision of professional organizations advocate the implementation of obligations by legal aid advocates. This study was conducted in Makassar, namely the Office of Perhimpunan Bantuan Hukum dan HAM Makassar (PBH2M), Legal Bantuan Hukum Makassar iLBHM), Pos Bantuan Hukum (Posbakum) District Court and the Religious Makassar. This type of research is used, ie empirical legal research. Sampling was done by purposive sampling. Data obtained through direct interviews and documentary study. The data were analyzed qualitatively and presented descriptively. The results showed that the application of the legal aid advocates have not run effectively and still limited, "here are constraints of the application delivery of the provision of legal assistance either through posbakum courts and legal aid organizations, including the associated allocation of funds, selection of beneficiaries legal and internal and external legal aid z<5sbakum on District Court and the Religious Makassar; supervision carried out by the awyers' organization is not optimal. The sanctions provided for in the Act does not expressly advocate enforced against lawyers who do not carry out the obligation to provide free legal aid to people seeking justice.

Keywords: Legal Aid, Advocate
\end{abstract}

\section{Abstrak}

Penelitian ini bertujuan untuk mengetahui (1) pelaksanaan pemberian bantuan hukum oleh advokat kepada masyarakat pencari keadilan, (2) bentuk pengawasan dari organisasi profesi advokat terhadap pelaksanaan kewajiban pemberian bantuan hukum oleh advokat. Penelitian ini dilaksanakan di Makassar, yaitu di Kantor Perhimpunan Bantuan Hukum dan HAM Makassar (PBH2M), Lembaga Bantuan Hukum Makassar (LBHM), Pos Bantuan Hukum (Posbakum) Pengadilan Negeri dan Pengadilan Agama Makassar. Tipe penelitian yang digunakan, yaitu penelitian hukum empiris. Pengambilan sampel dilakukan secara purposive sampling. Data diperoleh meialui wawancara langsung dan studi dokumentasi. Anaiisis data dilakukan secara kualitatif dan dipaparkan secara deskriptif. Hasil penelitian menunjukkan bahwa penerapan pemberian bantuan hukum oleh advokat belum berjalan efektif dan masih terbatas. Terdapat kendala-kendala dari penerapan pemberian bantuan hukum baik meialui posbakum pengadilan maupun lembaga bantuan hukum, antara lain yang terkait alokasi dana, seleksi penerima bantuan hukum dan kondisi internal maupun eksternal lembaga bantuan hukum, posbakum pada Pengadilan Negeri maupun Pengadilan Agama Makassar; pengawasan yang dilakukan oleh organisasi advokat tidak optimal. Sanksi yang diatur dalam Undang-Undang Advokat tidak tegas diberlakukan terhadap advokat yang tidak melaksanakan kewajiban pemberian bantuan hukum cuma-cuma terhadap masyarakat pencari keadilan. 


\section{PENDAHULUAN}

Bantuan hukum merupakan salah satu unsur yang prinsipil dan mesti ada dalam suatu negara yang berdasarkan hukum (rechtstaats) terkait dengan penegakan keadilan. Advokat sebagai salah satu penegak hukum mempunyai kewajiban untuk memberikan bantuan hukum kepada masyarakat pencari keadilan dalam kedudukannya sebagai suatu profesi yang mulia (officium nobile). Bantuan hukum sebagai perlindungan hak asasi manusia diberikan kepada setiap individu tanpa harus melihat dan membedakan latar belakangnya. Konsekuensi dari adanya hal tersebut maka setiap orang memiliki hak untuk dapat diperlakukan secara sama di hadapan hukum \{equality before the law). Hal ini sebagaimana yang diuraikan dalam Pasal 27 ayat (1) UUD 1945 yang menyatakan bahwa segala warga negara bersamaan kedudukannya di dalam hukum dan pemerintahan dan wajib menjunjung hukum dan pemerintahan itu dengan tidak ada kecualinya. Dalam Pasal 28 huruf D ayat (1) dan Pasal 28 huruf I ayat (1) UUD 1945 yang telah diamandemen tersebut juga kembali menegaskan adanya jaminan dan perlindungan atas hak asasi yang dimiliki oleh setiap warga negara.

Pemberian bantuan hukum merupakan bagian dari rekognisi dan perlindungan hak asasi manusia yang khusus diberikan kepada kaum miskin dan buta hukum dimana tujuan yang ingin dicapai dari pemberian bantuan hukum adalah untuk terwujudnya akses keadilan (access to justice) yang merata. Salah satu bentuk dari bantuan hukum tersebut adalah adanya pembelaan atau pendampingan dari seorang advokat (access to legal counsel).

Bantuan hukum (legal aid) perlu dibudayakan dalam masyarakat (legal culture). Melalui pembentukan Undang-Undang Advokat yang mengatur profesi advokat dan Undang-Undang Bantuan Hukum, dapat diharapkan adanya persepsi yang sama tentang bantuan hukum di antara polisi, jaksa, advokat, pengadilan, petugas lembaga pemasyarakatan, dan masyarakat (Winarta, 2011). Masalah bantuan hukum dalam kaitannya dengan akses terhadap keadilan merupakan hal yang rumit untuk dijelaskan. Hal ini disebabkan karena masalah akses mendapatkan keadilan bukan hanya masalah hukum saja melainkan juga merupakan masalah politik, bahkan lebih jauh lagi adalah masalah budaya. Permasalahan tersebut semakin bertambah suiit dengan timbulnya dampak sosial di bidang ekonomi dan berbagai bidang lainnya sebagai akibat dari adanya proses pembangunan, seperti semakin luasnya tingkat kemiskinan, semakin tingginya tingkat buta huruf, dan keadaan kesehatan masyarakat yang semakin buruk (Setiyono, 2008).

Dalam kedudukannya sebagai suatu profesi yang mulia atau iebih dikenal dengan istilah officium nobile maka advokat, berdasarkan UndangUndang Nomor 18 Tahun 2003 tentang Advokat, juga memiliki kewajiban dalam implementasi bantuan hukum untuk kaum miskin dan buta hukum. Secara ideal dapat dijelaskan bahwa bantuan hukum merupakan tanggung jawab sosial ' dari advokat. Oleh sebab itu maka advokat dituntut agar dapat mengalokasikan waktu dan juga sumber daya yang dimilikinya untuk orang miskin yang membutuhkan bantuan hukum secara cuma-cuma atau probono.

Kewajiban pemberian bantuan hukum oleh advokat sudah diatur dalam Kode etik profesi 
advokat yang menjelaskan bahwa advokat wajib memberikan bantuan hukum dan tidak membeda-bedakan klien yang ditangani walaupun klien tersebut menerima jasa hukum dari advokat tersebut secara cuma-cuma. Hal ini dipertegas lagi dalam Pasal 22 Undang-Undang Nomor 18 Tahun 2003 tentang Advokat yang menyebutkan bahwa advokat wajib memberikan bantuan hukum secara cuma-cuma kepada masyarakat pencari keadilan yang tidak mampu.

Dalam kedudukannya sebagai suatu profesi yang mulia (officium nobile) maka pemberian bantuan hukum tentunya merupakan kewajiban yang melekat secara hukum kepada setiap advokat. Pemberian bantuan hukum oleh advokat bukan hanya dipandang sebagai suatu kewajiban, namun harus dipandang pula sebagai bagian dari kontribusi dan tanggung jawab sosial (social contribution and social liability) dalam kaitannya dengan peran dan fungsi sosial dari profesi advokat. Penelitian ini bertujuan untuk mengetahui pelaksanaan pemberian bantuan hukum oleh advokat kepada masyarakat pencari keadilan serta bentuk pengawasan dari organisasi profesi advokat terhadap pelaksanaan kewajiban pemberian bantuan hukum oleh advokat.

\section{BAHAN DAN METODE \\ Lokasi Penelitian}

Penelitian ini dilakukan di Makassar, di Perhimpunan Bantuan Hukum dan HAM Makassar (PBH2M), Lembaga Bantuan Hukum Makassar (LBHM), Pos Bantuan Hukum (Posbakum) Pengadilan Negeri dan Pengadilan Agama di Makassar. Tips penelitian adalah penelitian hukum empiris, yaitu dengan mengkaji peraturan perundang-undangan dengan melihat implementasi penerapan bantuan hukum dan pengawasan organisasi profesi advokat terhadap pelaksanaan kewajiban pemberian bantuan hukum oleh advokat kepada masyarakat pencari keadilan.

\section{Jenis dan Sumber Data}

Jenis dan sumber data yang digunakan dalam penelitian ini adalah data primer (data yang diperoleh secara langsung dari sumber pertama melalui wawancara langsung dari responden yang terpilih yang berkompeten di lokasi penelitian dan data sekunder (data yang diperoleh dari sumber-sumber yang sudah tersedia, seperti dokumen-dokumen peraturan perundang-undangan dan literatur bacaan yang relevan).

\section{Teknik Pengumpulan Data}

Untuk memperoleh data yang diperlukan, maka dipergunakan teknik pengumpulan data melalui wawancara (fekhik pengumpulan data secara langsung kepada narasumber melalui tanya jawab secara lisan), dan studi kepustakaan (seperti dokumendokumen peraturan perundangundangan dan literatur bacaan yang relevan).

\section{Populasi dan Sampel}

Populasi dalam penelitian ini adalah seluruh advokat yang tergabung pada Perhimpunan Bantuan Hukum dan HAM Makassar(PBH2M), Lembaga Bantuan Hukum Makassar (LBHM), Pos Bantuan Hukum (Posbakum) Pengadilan Negeri dan Pengadilan Agama di Makassar yang menjadi objek penelitian yang pernah menangani perkara bantuan hukum cuma-cuma. Pengambilan sampel dilakukan dengan menggunakan teknik purposive sampling. 


\section{Analisis Data}

Data primer dan data sekunder yang diperoleh melalui kegiatan penelitian ini akan diidentifikasi menurut kelompok tujuan tertentu, selanjutnya akan dianalisis secara kualitatif, kemudian disajikan secara deskriptif, yaitu dengan menguraikan, menjelaskan, dan menggambarkan sesuai dengan permasalahan dalam penelitian ini.

\section{HASIL PENELITIAN}

Hasil penelitian menunjukkan bahwa peningkatan jumlah perkara yang ditplak untuk mendapatkan bantuan hukum dari $11,5 \%$ menjadi $14,4 \%$ yang mencakup perkara di bidang hukum perdata, pidana, publik dan perkara hubungan industrial dimana mayoritas penerima bantuan hukum bekerja sebagai buruh, mengalami peningkatan dari $41,6 \%$ menjadi $42,4 \%$, sedangkan minoritas penerima bantuan hukum yaitu yang tidak bekerja mengalami peningkatan dari $10 \%$ menjadi 15,9\%; Advokat yang dijatuhi sanksi karena melakukan pelanggaran terhadap Kode Etik Advokat Indonesia (KEAI) termasuk tidak melaksanakan kewajiban pemberian bantuan hukum, tidak pernah terpublikasikan dan masyarakat juga masih belum memperoleh informasi yang jelas tentang bagaimana melakukan pelaporan atau pengaduan dan apakah tindakan tersebut akan ditindaklanjuti atau tidak.

\section{PEMBAHASAN}

Penelitian ini menunjukkan bahwa penerapan bantuan hukum belum berjalan efektif dan optimal dimana terdapat hambatan-hambatan dari penerapan pemberian bantuan hukum dengan berbagai alasan yang meiatarbelakangi keterbatasan pemberian bantuan hukum sehingga masih terjadi penolakan pemberian bantuan hukum kepada masyarakat miskin dan buta hukum, baik melalui posbakum pengadilan maupun lembaga bantuan hukum mulai dari alokasi dana, seleksi penerima bantuan hukum, kondisi internal dan eksternal lembaga bantuan hukum dalam menyelesaikan masalah hukum masyarakat pencari keadilan dan diiain sisi, semakin dibutuhkannya bantuan hukum oleh masyarakat pencari keadilan dari advokat sebagai pemangku tugas yang mulia (officium nobile) dimana berkewajiban memberikan bantuan hukum kepada masyarakat pencari keadilan, terutama masyarakat yang miskin dan buta hukum; Pengawasan yang dilakukan cleh organisasi advokat tidak optimal dimana sanksi yang diatur dalam Undang-Undang Advokat tidak tegas diberlakukan terhadap advokat yang tidak melaksanakan kewajiban pemberian bantuan hukum cuma-cuma terhadap masyarakat pencari keadilan.

Berdasarkan Pasa! 14 Utl Bantuan Hukum, syarat-syarat untuk memperoleh bantuan hukum secara umum, meliputi: (1) Pemohon bantuan hukum harus memenuhi syarat-syarat: a. mengajukan permohonan secara tertulis yang berisi sekurang-kurangnya identitas pemohon dan uraian singkat mengenai pokok persoalan yang dimohonkan bantuan hukum; b.menyerahkan dokumen yang berkenaan dengan perkara; dan $\mathrm{c}$. melampirkan surai keterangan miskin dari lurah, kepala desa atau pejabat yang setingkat di tempat tinggal pemohon bantuan hukum. (2) Dalam hal pemohon bantuan hukum tidak mampu menyusun permohonan secara tertulis, permohonan dapat diajukan secara lisan. Mengenai prosedur bantuan hukum secara 
cuma-cuma ini mesti dilaksanakan sesuai dengan ketentuan perundangundangan yang berlaku dan kode etik advokat. Kemudian pelaksanaan pemberian bantuan hukum secara cuma-cuma dilaporkan oleh advokat kepada dfganisasi advokat atau lembaga bantuan hukum.

Dalam hal pelaksanaan pemberian bantuan hukum, sebagaimana teori yang dikemukakan oleh Aristoteles mengenai konsep pendistribusian keadilan bahwa distribusi yang adil ketika distribusi keadilan itu sesuai dengan nilai kebaikannya, yakni nilainya bagi masyarakat (Fauzan, 2006). Ini mengandung arti bahwa dalam memberikan bantuan hukum secara cuma-cuma, advokat harus memberikan perlakuan yang sama antara bantuan hukum cuma-cuma (prodeo) dengan pemberian bantuan hukum yang dilakukan dengan pembayaran jasa (honorarium) tanpa membeda-bedakan siapapun pencari keadilan yang datang padanya. Tujuannya agar tidak terjadi kesenjangan sosial ekonomi dan perlakuan hukum antara masyarakat kaya dengan masyarakat miskin dan buta hukum sebagai sesama pencari keadilan.

Kebutuhan akan keadilan adalah salah satu kebutuhan pokok manusia yang senantiasa didambakan oleh setiap orang, baik yang kaya maupun yang miskin (Sunggono, 2009). Jika selama ini masyarakat kaya sudah cukup banyak merasakan atau mengenyam keadilan dan masyarakat miskin sudah cukup terjauh daripada mendapat keadilan, maka sudah saatnya keadaan yang demikian tidak terjadi lagi. Dalam kaitannya dengan program bantuan hukum, khususnya bagi masyarakat miskin dan tidak mampu, pada dasarnya merupakan salah satu jalan untuk menuju ke pemerataan keadilan Yuwono, 2011).

Berkaitan dengan tanggung jawab moral yang dimiliki oleh advokat sebagai salah satu pilar dalam pelaksanaan sistem peradilan yang adil dan berimbang (fair trial), maka penulis sependapat dengan Adnan Buyung Nasution bahwa, advokat memiliki peran bukan hanya sebagai pembela konsitusi namun juga sebagai pembela hak asasi manusia (Nasution, 2007). Oleh karena itu, advokat memiliki fungsi sosial dalam pelaksanaan tugasnya, yaitu memberikan bantuan hukum secara cuma-cuma khususnya bagi kaum miskin dan buta hukum sebagai bagian dari hak asasi manusia yang dilindungi oleh undang-undang.

Akses masyarakat pencari keadilan dalam memperoleh bantuan hukum ini, terdapat 2 (dua) inisiatif cara memperoleri bantuan hukum: Pertama, masyarakat pencari keadilan yang datang langsung meminta bantuan hukum untuk penyelesaian perkaranya melalui posbakum maupun Iembaga bantuan hukum yang ada (bersifat pasif); atau Kedua, Posbakum pengadilan maupun Iembaga bantuan hukum yang berinisiatif untuk memberikan bantuan hukum sebelum diminta terlebih dahulu bantuannya (bersifat aktif).

Rumusan tentang pengawasan dan pengorganisasian profesi advokat sebagai salah satu subsistem dari sistem peradilan terdapat pada poin 17 IBA Standarts for The Independence of The Legal Profession (Universal Declaration On Independence of Justice, 1983). Di Indonesia, pengawasan profesi advokat diatur dalam Pasal 13 ayat (1) UU Advokat menjelaskan bahwa pelaksanaan pengawasan sehari-hari 
dilakukan oleh Komisi Pengawasan yang dibantuk oleh organisasi advokat. Adanya pengawasan ini dimaksudkan agar advokat dalam menjalankan profesinya seialu menjunjung tinggi kode etik dan peraturan perundang-undangan yang berlaku. Sesuai Pasal 13 ayat (1) UU Advokat, pengawasan sehari-hari terhadap advokat dilakukan oleh Komisr Pengawas, yang terdiri atas advokat senior, ahli atau akademisi, dan masyarakat. Keberadaan Dewan kehormatan hanya bersifat pasif, yang akan melakukan tindakan apabila ada pengaduan dari subjek hukum yang ditentukan dalam Pasal 11 Kode Etik Advokat Indonesia, selanjwtnya disingkat KEAI.

Dalam kaitannya dengan fungsi Komisi Pengawasan, komisi ini belum terlihat nyata, dimana komisi ini seyogyanya melaksanakan perannya dengan lebih efektif agar hasil temuan dalam pekerjaannya dapat digunakan sebagai salah satu sumber penegakan KEAI terhadap advokat yang melakukan pelanggaran. Di Indonesia, pengawasan bantuan hukum melalui Posbakum terhadap para penasihat hukum (advokat) dilakukan oleh Ketua Pengadilan, sesuai dengan Surat Kesepakatan Bersama No. KMA/005.SKBA/II/1987 No.M.03PR.008.95 Tahun 1987 tertanggal 6 Juli 1987 tentang Tata Cara Pengawasan, Penindakan, dan Pembelaan Diri Penasihat Hukum dilakukan oleh Ketua Pengadilan. Surat ini ditanda tangani oleh Kehakimah dan Ketua Mahkamah Agung.

Adapun bentuk pengawasan yang selama ini dilakukan oleh organisasi profesi lebih cenderung kepada adanya pelanggaranpelanggaran kode etik yang bukan bersifat tidak dilaksanakannya kewajiban pemberian bantuan hukum secara cuma-cuma oleh advokat. Kondisi dimana belum dilakukannya pengawasan secara optimal dari organisasi profesi terhadap pelaksanaan kewajiban pemberian bantuan hukum ini disebabkan oleh beberapa alasan, yaitu optimalisasi pemberlakuan sanksi yang tegas belum dilakukan secara optimal terhadap advokat yang tidak melaksanakan kewajiban pemberian bantuan hukum secara cuma-cuma, tidak adanya aturan mengenai teknis pelaksanaan kewajiban memberikan bantuan hukum secara cuma-cuma yang seharusnya dirumuskan oleh organisasi advokat, dan tidak adanya aturan yang bersifat teknis mengenai pelaksanaan pengawasan terhadap advokat yang tidak melaksanakan kewajiban memberikan bantuan hukum cuma-cuma.

Di dalam UU Advokat, ada pengkategorian tindakan yang dilarang untuk dilakukan oleh advokat. Menurut Pasal 6 UU Advokat, advokat dapat dikenai sanksi hukuman atas perbuatan hukum atau tindakannya dengan alasan (1)mengabaikan atau menelantarkan kepentingan kiien, (2)berbuat atau bertingkah laku dengan tidak patut terhadap lawan atau rekan seprofesinya, (3)bersikap, tingkah laku, bertutur kata, atau mengeluarkan pernyataan yang menunjukkan sikap yang tidak hormat terhadap hukum, peraturan perundang-undangan, atau pengadilan, (4)berbuat hal-hal yang bertentangan dengan kewajiban, kehormatan, atau harkat dan martabat profesi, (5)melakukan pelanggaran terhadap peraturan perundangundangan dan/atau perbuatan terceia, (6)melanggar sumpah/janji advokat dan/atau kode etik.

Pengaturan dalam UU 
Advokat tersebut adalah jenis tindakan hukum yang dikenai sanksi (hukuman) dan mempunyai kesamaan dengan tindakan hukum advokat di Amerika Serikat. Namun perbedaannya ialah bahwa pengaturan dalam Undang-Undang Advokat bersifat lebih umum, sedangkan di Amerika Serikat pengaturannya langsung rrienuhjuk bada ihsfifusi maupun orang dalam pelanggaran tersebut (Sinaga, 2011).

Sanksi terhadap advokat akibat pelanggaran KEAI dapat dikatakan sebagai konsekuensi telah dituangkannya kode etik tersebut dalam peraturan tertulis sehinggakode etik ini seperti hukuman dimana sanksi atas peristiwa hukum konkret dapat dijatuhkan dari luar (heteronom). Jika tidak, maka kode etik ini hanyalah seperti kaidah kepercayaan, kesusilaan, sopan santun, di mana sanksi atas kaidahkaidah tersebut berturut-turut berasal dari Tuhan, diri sendiri, masyarakat secara resmi atau seperti kaidah hukum tanpa sanksi (lex imperpecta) (Mertokusumo, 1998).

Dalam hal pelaksanaan kewajiban pemberian bantuan hukum oleh advokat tidak dapat diiepaskan dari peranan organisasi advokat itu sendiri. Hal ini dikarenakan alasan bahwa organisasi advokat berfungsi untuk melakukan pe.ngawasan Sebagaimana dijelaskan dalam Pasal 12 ayat (1) UU Advokat bahwa, pengawasan terhadap advokat dilakukan oieh organisasi advokat. Mengenai sanksi yang berkaitan dengan pemberian bantuan hukum, dalam Pasal 7 ayat (1) UU Advokat telah mengatur beberapa jenis sanksi, yaitu teguran lisan, teguran tertulis, pemberhentian sementara dan pemberhentian tetap dari prefesinya. Apabila dihubungkan dengan ketentuan Pasal 6 huruf (d) UU
Advokat, maka advokat yang tidak melaksanakan kewajiban pemberian bantuan hukum secara cuma-cuma dapat dikategorikan telah melakukan perbuatan yang bertentangan dengan kewajiban profesi sebagaimana yang dijelaskan dalam Pasal 22 ayat (1) UU Advokat bahwa advokat "wajib" memberikan bantuan hukum cumacuma kepada pencari keadilan yang tidak mampu. Oleh karena itu, maka sanksi-sanksi sebagaimana yang dijelaskan dalam Pasal 7 ayat (1) UU Advokat dapat diberlakukan kepada advokat yang tidak melaksanakan kewajiban pemberian bantuan hukum secara cuma-cuma.

Faktor pengawasan dan sanksi mempunyai kontribusi besar terhadap pelanggaran kode etik advokat, dan sampai saat ini, pelanggaran kode etik disebabkan oleh ketiadaan pengawasan dan sanksi (Kadafi, 2011). Meskipuri jenis findakah dan jenis sanksi sudah dipaparkan dengan jelas, kenyataannya, tidak adanya pengawasan yang ketat dari organisasi advokat dan masyarakat memperoleh informasi yang kurang lengkap mengenai pelaksanaan (penerapan) bantuan hukum. Selain itu, masyarakat juga masih belum memperoleh informasi yang jeias tentang bagaimana melakukan pelaporan atau pengaduan dan apakah tindakan tersebut akan ditindaklanjuti atau tidak. Meskipun selama ini ada advokat yang dijatuhi sanksi karena melakukan pelanggaran terhadap KEAI, sanksi tersebut tidak pernah terpublikasikan sehingga tidak mempunyai implikasi yang besar terhadap advokat tersebut. Sanksi tersebut akan menjadi efektif ketlka diumumkan karena akan ada sanksi sosial yang langsung dirasakan oleh advokat itu sendiri dan di lain sisi, masyarakat luas juga dapat mengstahui informasi tersebut. 


\section{KESIMPULAN DAN SARAN}

Penerapan pemberian bantuan hukum oleh advokat belum berjalan efektif dan masih terbatas. Terdapat kendala-kendala dari penerapan pemberian bantuan hukum baik melalui posbakum pengadilan maupun iembaga bantuan hukum. Pengawasan yang dilakukan oleh organisasi advokat tidak optimal. Sanksi yang diatur dalam UndangUndang Advokat tidak tegas diberlakukan terhadap advokat yang tidak melaksanakan kewajiban pemberian bantuan hukum cumacuma terhadap masyarakat pencari keadilan. Pemerintah perlu melakukan upaya sistematis dan membuat reguiasi yang mengoptimalkan penerapan bantuan hukum cuma-cuma oleh advokat. Organisasi profesi perlu melakukan pengawasan yang optimal dan bersifat aktif terhadap pelaksanaan kewajiban pemberian bantuan hukum advokat dengan melibatkan pihakpi'riak yang berkaitan dengan pemberian bantuan hukum cumacuma kepada masyarakat pencari keadilan dan segera merumuskan ketentuan yang bersifat teknis mengenai pelaksanaan kewajiban serta mekanisme pengawasan terhadap pemberian bantuan hukum secara cuma-cuma oleh advokat.

\section{DAFTAR PUSTAKA}

Adnan Buyung Nasution, (2007). Bantuan Hukum di Indonesia. Jakarta: Pustaka LP3ES Indonesia.

BamMrig Suhggdrio, Aries Hariantd, (2009). Bantuan Hukum dan Hak Asasi Manusia. Bandung: Mandar Maju.

Binziad Kadafi, (2011). Advokat Indonesia Mencari Legitimasi. Jakarta: Pusat
Studi Hukum dan Kebijakan Indonesia, bekerja sama dengan The Asia Foundation.

Frans Hendra Winarta, (2011).

Bantuan Hukum di

Indonesia; Hak untuk

Didampingi Penasihat

Hukum bagi Semua Warga

Negara. Jakarta: Elex

Media Komputindo.

Ismantoro Dwi Yuwono; (2011). Panduan Memilih dan Menggunakan Jasa Advokat. Yogyakarta: Pustaka Yustisia.

Ilyas, Muhammad, et al. "Supervision of Fair Execution for Civil Case Decision." JL Pol'y \& Globalization 70 (2018): 101.

Goysal, Annie Helena. "Kontradiktif Penerapan Azas

Retroactive Dalam Mengadili Hak Azasi Manusia di Pengadinal HAM Adhoc." Pleno Jure 4.5 (2015): 13-27.

Setiyono, (2008). Kajian Konseptual terhadap Peran dan Fungsi Sosial Protest Advokat berdasarkan Kode Etik Advokat juncto UndangUndang Nomor 18 Tahun 2003 tentang Advokat. Available from: www.hukumonline.com

Sudikno Mertokusumo, (1998). Mengenal Hukum. Yogyakarta : Liberty.

Husen, La Ode, et al. "Independence and Accountability, Supreme Court In The Implementation: The Power Of Judgment in Indonesia." Imperial Journal of Interdisciplinary Research 3.5 (2017): 1976-1981. 
Universal Declaration On Independence of Justice, (1983). World Conference On The Independence of Justice. Montreal: CIJL Bulletin.

Uzair Fauzan, Heru Prasetyo, (2006). Teori Keadilan. Yogyakarta: Pustaka Pelajar.

V.Harlen Sinaga, (2011). Dasardasar Profesi Advokat. Jakarta: Erlangga. 